\title{
KEARIFAN LOKAL TRIHITAKARANA SUKU TENGGER DALAM KELANGSUNGAN KONSERVASI RANU PANI
}

\author{
Reva Fadul Allah Dian Presilia ${ }^{1}$, Fitra Arief Syaviar ${ }^{1}$, Najatul Ubadati², Sumarmi ${ }^{1}$
}

Diterima 13 Juni 2018, Dipublikasikan 31 Oktober 2018

CPenulis (2018)

\begin{abstract}
Conservation is done to prevent damage from happening continuously. The Tengger Tribe community has a unique socio-cultural pattern related to the positive behavior of the community in the use of space and the environment. The purpose of this study is to examine the condition of Ranu Pani which is experiencing degradation due to environmental management that is not in accordance with the principles of conservation. Descriptive research method with qualitative approach. The research location was conducted in Ranu Pani Village, Lumajang Regency, East Java. Data collection is done by observation and literacy studies. Analysis in the form of descriptive analysis with a phenomenological approach. The hope of this research is to determine the steps to restore the condition of Ranu Pani according to conservation principles. So that the surrounding communities in the region can preserve the sustainability of the Ranu Pani ecosystem.
\end{abstract}

\section{Keywords}

Conservation, Local Wisdom

\section{PENDAHULUAN}

Taman Nasional Bromo Tengger Semeru (TNBTS) adalah kompleks area seluas sekitar $50.276 \mathrm{Ha}$ di wilayah pegunungan, meliputi tiga lanskap terkenal yaitu Gunung Bromo, Kaldera Tengger dan Gunung Semeru. Berdasarkan SK Dirjen PHKA No. 68/Kpts/Dj-VI/1998, zonasi TNBTS terdiri dari: Zona Inti 22.006 Ha; Zona Rimba 23.485,20 Ha; Zona Pemanfaatan Intensif $425 \mathrm{Ha}$; Zona Pemanfaatan Tradisional $2.360 \mathrm{Ha}$; dan Zona Rehabilitasi 2.000 Ha. Konsep Taman Nasional adalah kawasan pelestarian alam baik daratan maupun perairan yang mempunyai ekosistem asli, yang dikelola dengan sistem zonasi yang dimanfaatkan untuk tujuan penelitian, ilmu pengetahuan, pendidikan, menunjang budidaya, budaya, pariwisata dan rekreasi. Sayektiningsih, dkk (2008) menyatakan bahwa Dataran tinggi Bromo Tengger Semeru kekhasan berupa enclave dalam kawasan konservasi.

Taman Nasional Bromo Tengger Semeru (TNBTS) merupakan salah satu di antara beberapa taman nasional yang memiliki peranan penting dalam menjaga fungsi keseimbangan ekosistem kawasan yang ada di daerah sekitar Jawa Timur (Astriyantika, 2014). Di antara beberapa wilayah di TNBTS, salah satu desa yakni Ranu Pani yang nama desanya berasal dari Ranu (atau danau dalam bahasa Tengger) kecamatan Senduro Kabupaten Lumajang.

Namun kini kondisi Ranu Pani terancam rusak karena mengalami penyusutan luas yang signifikan. Dalam data tahun 1980-an tercatat Ranu Pani masih seluas 9 ha dengan kedalaman

1 Jurusan Geografi, Fakultas Ilmu Sosial, Universitas Negeri Malang revafadul21@gmail.com

2 Jurusan Biologi, Fakultas Matematika dan Ilmu Pengetahuan Alam 
$12 \mathrm{~m}$. Kini, luas Ranu Pani hanya 5,6 ha dengan kedalaman hanya $6 \mathrm{~m}$. Laju erosi lahan di sekitarnya menjadi salah satu penyebab penyempitan ranu (Irawari, 2012). Erosi yang berasal dari lahan pertanian di sekitar Ranu Pani terjadi terus-menerus sehingga terjadi sedimentasi yang menyebabkan pendangkalan Ranu Pani.

Sedimentasi atau pendangkalan yang terjadi di lokasi wisata Ranu (danau) Pani di Desa Ranu Pani, Kecamatan Senduro, Lumajang, mencapai 50 persen dari total luas lahan 9 hektare (Kusbiantoro, 2011). Sedimentasi atau pendangkalan terjadi karena adanya lumpur dan sampah rumah tangga ataupun sampah pertanian yang masuk ke danau. Lahan di sekitar Ranu Pani digunakan sebagai lahan pertanian yang menghasilkan sayur-sayuran seperti kentang, kubis serta tomat. Sedangkan sayur-sayuran tersebut termasuk dalam tanaman yang menyebabkan erosi tinggi pada tanah.

Kondisi yang semakin memperburuk kerusakan Ranu Pani yakni kehadiran Kiambang atau Salvania Molesta, orang lokal menyebutnya Gambas. Sudah sejak pertengahan 2010 Ranu Pani, diserang Gambas. Perkembangan Gambas ini sangat cepat, hingga kini ketebalan tumbuhan air ini mencapai $30 \mathrm{~cm}$ menutupi Ranu Pani. Tumbuhan ini berkembang biak dengan rhizoma atau sejenis akar. Kiambang dapat tumbuh dengan cepat dan cukup melimpah di persawahan, rawa, danau, kolam, atau genangan air (Warasto 2013). Salvinia Molesta ditetapkan sebagai salah satu dari 100 jenis tanaman asing dengan sifat invasi terburuk versi Internasional Union for Conservation of Nature (IUCN,2013).

Desa Ranu Pani dihuni sebagian besar oleh Suku Tengger. Salah satu pedoman dalam kearifan lokal Suku Tengger dalam hidup mereka adalah Trihitakrana. Yakni hubungan antara Tuhan dengan manusia, manusia dengan manusia, serta manusia dengan alam. Melalui penguatan nilai-nilai Trihitakarana mendorong mahasiswa melakukan penelitian terkait permasalahan tersebut. Berdasarkan hal tersebut diatas maka judul dari penelitian ini Kearifan lokal "Trihitakarana" Masyarakat Suku Tengger Terhadap Kelangsungan Konservasi di Taman Nasional Bromo Tengger Semeru (TNBTS) dan tujuannya adalah untuk mengetahui apakah kelangsungan konservasi di TNBTS dipengaruhi oleh kondisi kearifan lokal masyarakat Suku Tengger.

\section{METODE}

Metode penelitian yang digunakan adalah metode kualitatif. Adapun Rancangan penelitian ini menggunakan rancangan penelitian deskriptif kualitatif yaitu penelitian yang menghasilkan data deskriptif berupa kata-kata tertulis atau lisan dari orang-orang dan pelaku yang diamati. Penelitian ini bertujuan untuk mendeskripsikan dan menjelaskan tentang bagaimana kondisi Ranu Pani berkaitan dengan perilaku masyarakat Suku Tengger dalam mengelola lingkungan dengan berpedoman pada Trihitakarana. Lokasi penelitian dilakukan di Desa Ranu Pani, Kecamatan Senduro, Kabupaten Lumajang.

Peneliti hadir sebagai instrumen kunci di mana peneliti melakukan semua pengumpulan data melalui observasi, wawancara, dan dokumentasi. Peneliti melakukan Focus Group Discussion, metode terakhir untuk mengumpulkan data ialah lewat diskusi terpusat mengumpulkan beberapa tokoh masyarakat yang mengerti tentang Trihitakarana dan mengkaji perilaku masyarakat dalam menjaga lingkungan, diskusi dilakukan secara Intens untuk mendapatkan hasil pemaknaan yang lebih objektif. 
Sumber data yang digunakan adalah sumber data primer dan sumber data sekunder. Sumber data primer diperoleh dari pengambilan data secara langsung. Sedangkan sumber data sekunder diperoleh dari perantara seperti dokumen pemerintahan.

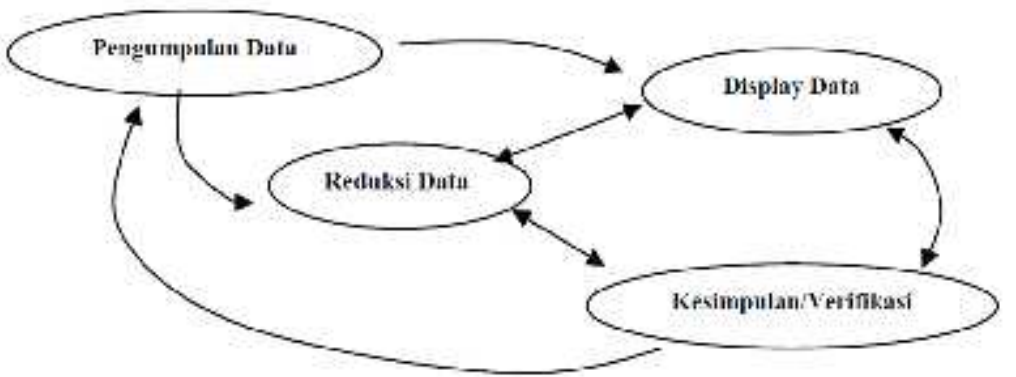

Gambar 1. Komponen Analisis Data: Model Interaktif (Sumber: Miles dan Huberman, 1992:20)

\section{HASIL DAN PEMBAHASAN}

Trihitakarana pada hakikatnya adalah "sikap hidup yang seimbang antara memuja Tuhan dengan mengabdi pada sesama manusia serta mengembangkan kasih sayang pada sesama manusia serta mengembangkan kasih sayang pada alam lingkungan" (Wiana dalam Purana. 2016). Konsep hidup yang sangat ideal ini diterapkan abad kesebelas, yang bertujuan menata kehidupan umat Hindu. "Manut Lingih Sang Hyang Aji", artinya menata kehidupan berdasarkan ajaran kitab suci. Di setiap desa pakraman dibangun Kahyangan Tiga untuk sang catur warna. Desa pakraman itu merupakan tempat/wadah sang catur asrama dan catur warna untuk mewujudkan tujuan hidupnya mencapai catur warga (dharma, artha, kama, dan moksah). Di desa pakraman diciptakan suatu tatanan untuk mengembangkan cinta kasih pada alam lingkungan beserta isinya. Hal ini sesuai dengan yang tercantum dalam kitab "Sarasamuscaya (135) dengan istilah Prihen Tikang Bhuta Hita", artinya usahakan kesejahteraan semua makhluk itu akan menjamin tegaknya catur marga atau empat tujuan hidup yang terjalin satu sama lainnya.

Konsepsi dasar Tri Hita Karana tercantum dalam Kitab Suci Bhagawad Gita III. 10 dinyatakan bahwa yadnyalah yang menjadi dasar hubungan Tuhan Yang Maha Esa (Prajapati), manusia (praja) dan alam (kamaduk). Berdasarkan pernyataan itu dapat dinyatakan bahwa Tri Hita Karana adalah dasar untuk mendapatkan kebahagiaan hidup apabila mampu melakukan hubungan yang harmonis berdasarkan yadnya (ritual, korban suci) kepada Ida Sang Hyang Widhi dalam wujud bakti (tulus) kepada sesama manusia dalam wujud pengabdian dan kepada alam lingkungan dalam wujud pelestarian alam dengan penuh kasih.

Harmonisasi dan dinamisasi berdasarkan yadnya dari tiga unsur sebagai sebab (karana) datangnya kebahagiaan hidup (hita) atau "tiga penyebab kedatangan kebahagiaan". Berdasarkan rumusan dalam Bhagawad Gita III.10 di atas dapat dinyatakan bahwa, secara filosofis Tri Hita Karana adalah membangun kebahagiaan dengan mewujudkan sikap hidup yang seimbang antara berbakti kepada Sang Hyang Widhi, mengabdi kepada sesama umat manusia dan menyayangi alam lingkungan berdasarkan yadnya.

Konsep Tri Hita Karana juga diterapkan pada masyarakat Suku Tengger di Taman Nasional Bromo Tengger Semeru. Khususnya hubungan manusia dengan lingkungan alamnya, dapat dilihat dari cara masyarakat Suku Tengger dalam mengelola lingkungan. Manusia memperoleh bahan keperluan hidup dari lingkungan, dengan demikian manusia sangat tergantung pada lingkungan. Oleh karena itu manusia harus selalu memperhatikan lingkungannya, lingkungan harus terjaga dan terpelihara, tidak boleh dirusak, hutan tidak boleh ditebang semuanya karena dapat merusak keseimbangan alam. Manusia harus memberikan timbal balik positif berkaitan dengan pengelolaan lingkungan. 
Masyarakat Suku Tengger memiliki upaya dalam melaksanakan konservasi lingkungan. Beberapa upaya yang dilakukan adalah mulai melaksanakan pertanian dengan sistem terasering, menjaga kebersihan lingkungan desa dari sampah wisatawan. Hal ini terlihat dengan adanya tong sampah di sudut-sudut yang strategis. Selain itu, masyarakat Suku Tengger dalam menghadapi kondisi Ranu Pani berupaya dalam melakukan pembersihan kiambang secara manual setiap harinya.

Proses pembersihan secara manual adalah dengan menggunakan alat-alat tradisional seperti garu bambu, garu besi, karung bekas, tali tambang, serta bambu panjang. Bagian danau yang tertutup Kiambang dibagi menjadi beberapa plot terlebih dahulu. Kemudian bagian-bagian tersebut dibatasi oleh bambu panjang hingga menjadi bagian kotak-kotak. Setelah itu, Kiambang digiring secara manual menggunakan bambu hingga ke tepi. Pada saat Kiambang telah berada di tepian danau, warga beramai-ramai menyekop Kiambang menggunakan garu bambu ke tumpukan di pinggir danau. Warga yang lain juga menggunakan karung bekas untuk menjaring kiambang dan dilempar ke tepi. Kiambang yang ditumpuk di tepi akan dibiarkan mengering, kemudian dimanfaatkan sebagai pupuk organik oleh warga.

Lingkungan Ranu Pane yang termasuk dalam kawasan Taman Nasional Bromo Tengger Semeru. Hal ini juga menjadi salah satu faktor penting dilakukannya upaya konservasi oleh masyarakat. Selain terletak di kawasan taman nasional, lingkungan Ranu Pane juga menjadi objek wisata yang memiliki potensi besar dalam mengalami kerusakan. Oleh karena itu, masyarakat melakukan upaya-upaya konservasi lingkungan.

Nilai yang mendasar sebagai urgensi dalam merekonstruksi kearifan lokal adalah korelasi nilai-nilai Trihitakaran dengan kaidah konservasi. Nilai Trihitakarana yang mengatur aspek sosial, ekonomi, agama, budaya. Pembagian wilayah atau sistem Tat Twam Asi sebagai ajaran bagaiamana hidup rukun dan harmonis dalam suasana multikultural. Tat Twam Asi yang berarti aku adalah engkau dan engkau adalah aku, kedua konsep Trihitakarana dan Tat Twam Asi sebagai konsep untuk mewujudkan hidup yang harmonis. Kedua konsep tersebut bukan hanya diketahui namun juga diketahui dan dipahami dan diamalkan dengan sebaik mungkin di masyarakat sehingga suasana menjadi dambaan bersama dapat dirasakan. Trihitakarana terdiri dari Parahyangan (keharmonisan manusia dengan Tuhan), Pawongan (keharmonisan hubungan sesama umat manusia) dan Palemahan (keharmonisan hubungan manusia dengan alam).

Pada bagian Palemahan ajaran ini menekankan kepada umat manusia untuk tetap menjaga kelestarian lingkungan alam sekitar, sehingga terwujud keharmonisan alam dan tetap terjaga ekosistem. Untuk mewujudkan keharmonisan dengan alam lingkungan, bentuk-bentuk nyata yang dapat dipedomani dan dilaksanakan khususnya bagi umat Hindu adalah melalui makna Tumpek Uduh, Tumpek Kandang dan Caru (Bhuta Yajna) dengan berbagai tingkatannya. Semua merupakan suatu tatanan mendasar serta mengandung konsep-konsep keseimbangan yang pada intinya memberikan dorongan untuk menumbuh kembangkan rasa sesama alam lingkungannya. Dengan merekonstruksi nilai Trihitakarana khususnya Palemahan untuk menyelamatkan kondisi Ranu Pani. Terdapat jelas bahwa dalam Palemahan, manusia wajib untuk menjaga keseimbangan ekosistem alam agar manusia mencapai keharmonisan hidup.

\section{SIMPULAN}

Danau Ranu Pani merupakan danau yang terletak di kawasan konservasi namun justru mengalami krisis konservasi. Sistem pengelolaan lahan menyebabkan permasalahan seperti sedimentasi dan juga eutrofikasi pada danau tersebut. Jika tidak dilakukan upaya konservasi, maka danau tersebut terancam rusak dan hilang.

Suku Tengger yang mendiami Desa Ranu Pane memiliki kearifan lokal berkaitan dengan cara hidup yang merujuk pada Kitab Weda yakni Trihitakarana. Konsep Trihitakarana yang mengatur bagaimana mencapai keharmonisan hubungan. Tiga hal tersebut meliputi Parahyanagan, Pawongan dan Palemahan. Dalam Parahyangan mengatur bagaimana 
tercapainya hubungan harmonis antara manusia dengan Tuhan, sedangkan Pawongan mengajarkan bagaimana menjaga keharmonisan hubungan dengan manusia. Serta Palemahan mengajarkan bagaimana menjaga keseimbangan hubungan dengan alam.

Palemahan mewajibkan manusia menjaga lingkungannya baik dari segi perilaku, menumbuhkan rasa cinta kasih terhadap lingkungan. Melalui rekonstruksi nilai-nilai kearifan lokal dapat memberikan informasi bagi masyarakat Ranu Pane secara khusus dan masyarakat pendatang secara umum. Hal tersebut juga mampu mendorong masyarakat luas agar menjaga lingkungan berbasis kearifan lokal.

\section{DAFTAR PUSTAKA}

Astriyantika, Meyliana. Harnios Arief. Tutut Sunarminto. 2014. Studi Konservasi

Irawari, Dahlia. "Mencoba Menyelamatkan Ranu Pani” Kompas.com edisi tanggal 28 April 2012.https://nasional.kompas.com/read/2012/04/28/03293049/Mencoba.Menyelamatkan.R anu.Pani Diakses pada 30 April 2018

Kusbinatoro, Didik. "SedimentasiWisata Ranu Pane Capai 50 Persen" Antara.com edisi tanggal 15 Desember 2011 https://jatim.antaranews.com/berita/78452/sedimentasi-wisataranu-pane-capai-50-persen Diakses pada 30 April 2018

Miles, Matthew dan Huberman, A. Michael. 1992. Analisis Data Kualitatif: Buku Sumber Tantang Metode-Metode Baru. Jakarta:UI Press.

Purana, I. 2016. Pelaksanaan Tri Hita Karana Dalam Kehidupan Umat Hindu Jurnal Kajian Pendidikan Wisdya Accarya, (Online) ISSN - 2085-0018

http://studylibid.com/doc/493870/pelaksanaan-tri-hita-karana-dalam-kehidupan-umat diakses pada 30 Maret 2018

Sayektiningsih, dkk. 2008. Strategi Pengembangan Pendidikan Konservasi Pada Masyrakat Suku Tengger di Enclave TNBTS http://journal.ipb.ac.id/index.php/konservasi/article/view/3043/2009 Diakses pada 30 April 2018

Warasto., Yulisman., M. Fitriani. 2013. Tepung Kiambang (Salvinia molesta) Terfermentasi Sebagai Bahan Pakan Ikan Nila (Oreochromis niloticus). Jurnal Akuakultur Rawa Indonesia. Vol. 1(2) : 173-183. 